\title{
Wnt-3a and Wnt-3 differently stimulate proliferation and neurogenesis of spinal neural precursors and promote neurite outgrowth by canonical signaling
}

\begin{tabular}{|c|c|}
\hline Journal: & Journal of Neuroscience Research \\
\hline Manuscript ID: & Draft \\
\hline Wiley - Manuscript type: & Research Article \\
\hline $\begin{array}{l}\text { Date Submitted by the } \\
\text { Author: }\end{array}$ & \\
\hline Complete List of Authors: & $\begin{array}{l}\text { David, Monica; IRBLLeida-Univ. of Lleida, CMB } \\
\text { Cantí, Carles; IRBLLeida-Univ of Lleida, MEX } \\
\text { Herreros, Judit; IRBLleida-Univ of Lleida, CMB }\end{array}$ \\
\hline Keywords: & $\begin{array}{l}\text { WNTs, Neuronal progenitors, Neurite outgrowth, Neural precursors, } \\
\text { Beta catenin }\end{array}$ \\
\hline
\end{tabular}

\section{S) ScholaroNE"}


Wnt-3a and Wnt-3 differently stimulate proliferation and neurogenesis of spinal neural precursors and promote neurite outgrowth by canonical signaling

Monica D. David, Carles Cantí \& Judit Herreros*

Laboratori d'Investigació, Hospital Universitari Arnau de Vilanova, Departament de Ciències Mèdiques Bàsiques, IRBLleida-University of Lleida, Spain.

*Corresponding author: j.herreros@cmb.udl.cat

Phone: 0034973702215

Fax: 0034973702213

Running title: Wnts regulate spinal neural precursor development.

This work was funded by grants from Institute of Health Carlos III (PI042605, PI080790) and Generalitat de Catalunya (2005SGR00628). 


\begin{abstract}
Wnt factors regulate neural stem cell development and neuronal connectivity. Here we investigated whether Wnt-3a and Wnt-3, expressed in the developing spinal cord, regulate proliferation and the neuronal differentiation of spinal cord neural precursors (SCNP). Wnt-3a promoted a sustained increase of SCNP proliferation, whereas Wnt-3 enhanced SCNP proliferation transiently and increased neurogenesis through $\beta$-catenin signaling. Consistent with this, Wnt-3a and Wnt-3 differently regulate the expression of Cyclin-dependent kinase inhibitors. Furthermore, Wnt-3a and Wnt-3 stimulated neurite outgrowth in SCNP-derived neurons through ß-catenin and TCF4-dependent transcription. GSK-3ß inhibitors mimicked Wnt signaling and promoted neurite outgrowth in established cultures. We conclude that Wnt-3a and Wnt-3 signal through the canonical Wnt/ $\beta$-catenin pathway to regulate different aspects of SCNP development. These findings may be of therapeutic interest for the treatment of neurodegenerative diseases and nerve injury.
\end{abstract}

Key words: Neural stem cells, neuronal differentiation, Glycogen-synthase-kinase (GSK)-3ß, T-Cell Factor (TCF). 


\section{INTRODUCTION}

Neurons in the central nervous system (CNS) originate from embryonic neural precursors (NP) that proliferate at the subventricular zone. The maintenance, proliferation and differentiation of NPs are controlled by local signals at the stem cell niche. Wnt factors, a family of secreted glycoproteins, are important regulators of the proliferation, self-renewal, specification and differentiation of NPs in the CNS. Wnt-1 and Wnt-3a control spinal cord dorsal interneuron specification (Murashov et al. 2005; Muroyama et al. 2002). Different Wnts distinctly regulate proliferation and neurogenesis of developing midbrain NPs (Andersson et al. 2008; Castelo-Branco et al. 2003; Hirabayashi et al. 2004; Sousa et al. 2009). Wnt-7a directs the neuronal differentiation of cortical NPs (Hirabayashi et al. 2004). In addition, Wnt-3 regulates neurogenesis and Wnt-7a stimulates NP self-renewal and proliferation in the adult brain (Lie et al. 2005; Qu et al.).

Wnts signal through three main pathways: the canonical Wnt/ß-catenin, the planar cell polarity and the calcium pathways (Ciani and Salinas 2005; Logan and Nusse 2004; Michaelidis and Lie 2008). In the canonical pathway, Wnts inhibit GSK-3ß, resulting in ß-catenin cytoplasmic stabilization, translocation to the nucleus and transcription by $\mathrm{TCF} /$ Lef factors of target genes. It is well documented that $\beta$-catenin controls the expansion of NP populations through TCF activity (Chenn and Walsh 2002; Gulacsi and Anderson 2008; Zechner et al. 2003). Thus B-catenin stabilization results in enlarged brain and spinal cord, whereas loss of B-catenin reduces brain size and increases neuronal differentiation (Gulacsi and Anderson 2008; Woodhead et al. 2006). In agreement with these findings, the dorsal neural tube is reduced in size in Wnt-1/Wnt-3a mutant mice (Ikeya et al. 1997). In contrast, ß-catenin 
stabilization increases neuronal differentiation of embryonic stem cells and NP (Castelo-Branco et al. 2004; Hirabayashi et al. 2004; Otero et al. 2004). Therefore, activation of the $\mathrm{Wnt} / \mathrm{\beta}$-catenin signaling regulates proliferation and neuronal differentiation of NP highly depending on the cellular context and the developmental stage (Hirabayashi et al. 2004).

Wnt-3a and Wnt-3 are expressed at dorsal areas of the developing spinal cord (Megason and McMahon 2002; Parr et al. 1993). Interestingly, Wnt-3 is also expressed around the ventricular zone as well as by lateral motoneurons (Krylova et al. 2002; Megason and McMahon 2002). It was proposed that dorsal Wnt-1 and Wnt-3a display mitogenic activities that shape the growth of the spinal cord (Megason and McMahon 2002). Here we investigated the roles of Wnt-3a and Wnt-3 factors in spinal cord neural precursor (SCNP) development. We found that both Wnt-3a and Wnt-3 promoted SCNP proliferation. Contrary to the mitogenic effect of Wnt-3a, Wnt-3 increased SCNP proliferation only transiently and enhanced neurogenesis. Furthermore, Wnt-3a and Wnt-3 stimulated neurite outgrowth. GSK-3ß inhibitors promoted or reduced neurite extension depending on the stage of neurite outgrowth, suggesting distinct roles of GSK-3ß during neurite development. Finally, ß-catenin and transcription by TCF4 were required for neurogenesis and neurite outgrowth induced by Wnts. These findings identify a role for canonical Wnt/ß-catenin signaling in SCNP-derived neuronal differentiation (including neurogenesis and neurite extension). Our results uncover similar actions of Wnt-3a and Wnt-3 during neurite outgrowth and a distinct regulation of cell cycle entry/exit by Wnt factors in SCNP proliferation/neurogenesis. 


\section{MATERIAL AND METHODS}

Spinal cord neural precursor (SCNP) culture. Mouse embryonic day 12.5-13 spinal cords were dissociated, after cleaning off the meninges, in phosphate buffer saline (PBS) plus 0.6\% glucose using Pasteur pipettes (Wu et al. 2003). Cells were grown on plates coated with poly-2-hydroxyethyl-methacrylate (Sigma) in DMEM:F12 medium (Invitrogen) supplemented with B27 (Invitrogen) and basic Fibroblast Growth Factor (bFGF 20ng/ml; Invitrogen). The resulting neurospheres were grown for one to four weeks. Following neurosphere dissociation (Trypsin $0.25 \%$; Invitrogen), cells plated on poly-D-lysine (10 $\mu \mathrm{g} / \mathrm{ml}$; Sigma) and laminin (4 $\mu \mathrm{g} / \mathrm{ml}$; Sigma) pre-coated glass coverslips or plastic wells in DMEM:F12 supplemented with B27 and 1\% Fetal Calf Serum (FCS; Invitrogen) at $75-400$ cells $/ \mathrm{mm}^{2}$ in the absence of bFGF.

Control and Wnt-3 conditioned media. Control Rat1B cells or stably expressing hemagglutinin(HA)-tagged Wnt-3 (provided by Dr. A. Munsterberg, Norwich) were maintained in DMEM (Invitrogen), 10\% FCS and Geneticin $250 \mu \mathrm{g} / \mathrm{ml}$ (Invitrogen). To obtain control or Wnt-3 conditioned media (CM), cells were conditioned overnight in DMEM:F12 and B27 medium. CMs were centrifuged, diluted 1:1 with fresh medium and changed daily. The level of HA-Wnt-3 was monitored by Western-blot. Control experiments incubating SCNP with dialyzed sodium azide free anti-Wnt-3 antibodies (20 $\mu \mathrm{g} / \mathrm{ml}$; Santa Cruz;) together with Wnt-3 CM showed a blockade of the effects induced by Wnt-3 CM (data not shown), indicating that they were due to Wnt-3.

Cell treatments. SCNP were stimulated with $50 \mathrm{ng} / \mathrm{ml}$ Bovine Serum Albumin (BSA), $50 \mathrm{ng} / \mathrm{ml}$ Wnt-3a (R\&D), control CM or Wnt-3 CM from the time of plating for 2-4 days in vitro (DIV). The effect of Wnt-3a (50 ng/ml) was maintained within the 5-200 
$\mathrm{ng} / \mathrm{ml}$ range. Kenpaullone (Sigma; $15 \mu \mathrm{M}$ ) and BIO (6-bromoindirubin-3-oxime, Calbiochem; $1 \mu \mathrm{M}$ ) were added from plating (DIV0-3) or from day 2 to day 3 (DIV2-3) and cultures were fixed at 3DIV. Actinomycin D (ActD, 5nM; Sigma) was added from plating and cultures fixed at 2DIV. Recombinant mouse Frizzled-8 cystein-rich domain/Fc chimera and Dikkopf-1 (R\&D) were incubated at 100 or $300 \mathrm{ng} / \mathrm{ml}$ together with BSA, Wnt-3a, control CM or Wnt-3 CM from plating up to 4 DIV. All media was changed every other day, except for control and Wnt-3 CM that were changed daily.

Flow cytometry analysis (FACS). SCNP stimulated with BSA/Wnt-3a or control/Wnt$3 \mathrm{CM}$ for 2DIV were trypsinized and fixed by resuspension in PBS and 70\% ethanol (2 hours, $4^{\circ} \mathrm{C}$ ). Cells were incubated with $0.1 \%$ Triton $\mathrm{X}-100,50 \mu \mathrm{g} / \mathrm{ml}$ of propidium iodide and $50 \mu \mathrm{g} / \mathrm{ml}$ of RNAse A (all from Sigma; $30 \mathrm{~min}, 37^{\circ} \mathrm{C}$ ) before DNA content analysis on EPICS-XL flow cytometer (Coulter).

Real time RT-PCR. Total RNA was isolated from SCNP cultures treated with BSA, Wnt-3, control or Wnt-3 CM up to 4DIV using the RNAeasy kit (Qiagen) including the DNAse digestion step. For reverse transcription, 0,5-1 $\mu \mathrm{g}$ of RNA was incubated 2 min at $90^{\circ} \mathrm{C}$ and the reaction was performed in $6.25 \mathrm{mM} \mathrm{MgCl}_{2}, 2 \mathrm{mM}$ dNTPs mix, $2.5 \mathrm{mM}$ random hexamers, $20 \mathrm{U}$ of RNAse inhibitor and $50 \mathrm{U}$ of Multiscribe ${ }^{\mathrm{TM}}$ (all from Applied Biosystems; $10 \mathrm{~min}, 25^{\circ} \mathrm{C} / 60 \mathrm{~min}, 42^{\circ} \mathrm{C} / 5 \mathrm{~min}, 95^{\circ} \mathrm{C}$ ). RT- control samples were run in paral.lel without the addition of reverse transcriptase. Real-time RT-PCR was performed in triplicate using $1 \mu \mathrm{l}$ of cDNA or RT- sample, Taqman Master Mix ${ }^{\mathrm{TM}}$ (Applied Biosystems) and FAM-labeled probes spanning different exons specific for mouse p57 (Mm00438170_m1), p27 (Mm00438168_m1) and $\beta$-actin (4352933E) as a housekeeping gene in a ABI Prism 7000 detection system (Applied Biosystems; 2 min, 
$50^{\circ} \mathrm{C} / 10 \mathrm{~min} 95^{\circ} \mathrm{C} / 15 \mathrm{sec}, 95^{\circ} \mathrm{C}$ and $30 \mathrm{sec}, 60^{\circ} \mathrm{C}$ repeated for 50 cycles). Relative mRNA expression levels were calculated by subtracting the value of the housekeeping gene and calculated as $2^{-\Delta \Delta \mathrm{Ct}}$ according to the manufacturer's instructions.

Antibodies. Antibodies against Nestin and NeuN were from Chemicon, anti-BrdU from Dako, anti- $\beta$-catenin from BD, anti- $\beta$ III-tubulin from Covance, anti- $\beta$-actin from Sigma and anti-EGFP/GFP from Abcam.

\section{Bromodeoxiuridine (BrdU) incorporation, immunocytochemistry and} morphometric measurements. BrdU $3.75 \mu \mathrm{g} / \mathrm{ml}$ was applied for 8 hours at 2DIV or 4DIV before fixation with 4\% paraformaldehyde. Immunocytochemistry was performed as described (David et al. 2008). For BrdU immunodetection, cells were permeabilized with $0.05 \%$ Triton $\mathrm{X}-100$, incubated with $2 \mathrm{~N} \mathrm{HCl}\left(30 \mathrm{~min}, 37^{\circ} \mathrm{C}\right)$ and neutralized with $0.1 \mathrm{M}$ sodium tetraborate, $\mathrm{pH}=8,5$ (2 $\mathrm{min}, \mathrm{RT})$ before blocking. Micrographs were obtained using an inverted Olympus IX70 microscope (10x, 0.3 NA and 20x, 0.4 NA) equipped with epifluorescence optics and a camera (Olympus OM-4 Ti).

To calculate the percentage of total proliferation, the number of proliferating SCNP (BrdU and nestin-positive) was referred to the total number of cells stained by Hoechst. Alternatively, we calculated the percentage of BrdU incorporation in small neuroblasts (defined as nestin-positive SCNP with a cell body diameter of $\sim 15 \mu \mathrm{m}$ and displaying short neuritic-like processes) by counting small neuroblasts co-stained for BrdU and nestin referred to its total number. For neurogenesis, the number of BIII-tubulinimmunoreactive neurons was referred to the total number of cells stained by Hoechst at 4DIV. The length of all BIII-tubulin immunoreactive neurites was measured using Adobe Photoshop. 
All plots represent average \pm s.e.m. ( $n=3-6$ experiments; 80 cells counted or measured on average per condition and experiment). Significance was calculated by the Student T test $(* \mathrm{p} \leq 0.05, * * \mathrm{p} \leq 0.01$ and $* * * \mathrm{p} \leq 0.001)$.

ShRNA expression by lentiviral infection. Specific 19 nucleotide sequences were chosen using RNAi design interfaces. Primers were designed against the sequences GGGTTCTGATGATATAAAT (shRNA1) and GTTTGTGCAGTTGCTTTAT (shRNA2) for mouse B-catenin and cloned into pSUPER. A fragment containing the H1 promoter for the RNA pol III and the shRNA sequence was subcloned into the pLVTHM plasmid (from Dr. D. Trono, Geneva). shRNA vectors were transfected into HEK293T together with psPAX2 and pMD2G and the viral pellet was obtained (David et al. 2008). Transfection efficiency ( 90\%) was analyzed by GFP expression driven by pLVTHM. SCNP were transduced with lentivirus expressing shRNAs 2 hours after plating and treated with BSA, Wnt-3a, control or Wnt-3 CM from 3DIV to 5DIV. Cells were fixed for GFP/ßIII-tubulin immunostaining and analyzed for neurogenesis or neurite outgrowth at 5DIV. Alternatively, cultures were lysed in $62.5 \mathrm{mM}$ Tris-HCl, pH 6,8 and $2 \%$ SDS for Western-blot.

Nucleofection. Expression of EGFP alone or dominant-negative $\triangle$ N-TCF4-HA plus EGFP (3:1) was achieved using the Nucleofector (Amaxa) upon neurosphere disgregration. SCNP were sub-plated at 300 cells $/ \mathrm{mm}^{2}$, treated 4 hours after plating with Wnts, fixed at 2DIV and immunostained for EGFP and HA (only cells coimmunostained were measured for neurite length using the EGFP immunostaining). 


\section{RESULTS}

\section{Wnt-3a and Wnt-3 increase SCNP proliferation}

The expression patterns of Wnt-3a and Wnt-3 in the developing spinal cord (Krylova et al. 2002; Megason and McMahon 2002; Parr et al. 1993) prompted us to study Wnt-3a and Wnt-3 signaling in mouse SCNP cultures. Since purified Wnt-3 is not available, we used CMs obtained from Rat1B-cells stably expressing Wnt-3 or control cells (Krylova et al. 2002; Purro et al. 2008). We first investigated a possible effect of Wnt-3a/Wnt-3 in SCNP proliferation by FACS analysis. Wnt-3a and Wnt-3 treatments increased the percentage of cells in S phase compared to the corresponding control by $29 \%$ and $41 \%$ at $2 \mathrm{DIV}$ after $48 \mathrm{~h}$ of Wnt stimulation (Fig. 1A). We also performed BrdU incorporation assays in SCNP cultures co-immunostained for nestin. Nestin immunostaining revealed heterogeneous morphologies of SCNP (Fig. 1B). Therefore, we calculated the percentage of cells that incorporated BrdU referred to all SCNP (total BrdU incorporation) and in small neuroblasts, defined as nestin-positive SCNP with a cell body diameter of $\sim 15 \mu \mathrm{m}$ and short neurite-like processes. Cultures treated with Wnt-3a and Wnt-3 up to 2DIV showed an increase of total BrdU incorporation of $68 \%$ and $71 \%$, respectively, compared to controls (Fig. 1C). Wnt-3a and Wnt-3 treatments also promoted BrdU incorporation in small neuroblasts by $19 \%$ and $20 \%$, respectively, at 2DIV (Fig. 1C). At 4DIV, Wnt-3a still increased BrdU incorporation (total BrdU incorporation by $86 \%$ and BrdU incorporation in small neuroblasts by $63 \%$ compared to control; Fig 1C). However, Wnt-3 did not affect BrdU incorporation (total or in small neuroblasts) compared to the control at 4DIV (Fig. 1C). These results suggest that Wnt3a maintains SCNP in a proliferative state, whereas Wnt-3 stimulates their proliferation only transiently. 
To complement these findings, we performed real-time RT-PCR analysis of cyclindependent kinase (Cdk) inhibitors (p57/kip2 and p27/kip1) expression from 4DIV control, Wnt-3a- or Wnt-3-treated SCNPs. Wnt-3a significantly decreased the expression of p57 and p27 vs control, whereas Wnt-3 increased their expression levels vs control samples (Fig. 1D). These findings are in agreement with the presence of putative TCF binding elements in the promoter region of the p57 and p27 (data not shown) and suggest that Wnt factors differently regulate SCNP proliferation/cell cycle exit at a transcriptional level.

\section{Wnt-3 increases neurogenesis from SCNP by canonical Wnt/ß-catenin pathway}

The transient increase in BrdU incorporation and the increased expression of $\mathrm{Cdk}$ inhibitors upon Wnt-3 stimulation suggested that SCNP exit the cell cycle after Wnt-3 treatment. Therefore we studied neurogenesis in Wnt-treated SCNP. Wnt-3 increased by approximately $40 \%$ the proportion of neurons (immunolabelled for the early neuronal marker ßIII-tubulin) referred to the total number of cells at 4DIV (Fig. 2A, 2B and 4A), which also express the post-mitotic marker NeuU (Fig. 2D). The percentage of BIIItubulin-immunoreactive neurons was not affected by Wnt-3a treatment (Fig. 2A), consistent with its effect inducing proliferation at 4DIV (Fig. 1C).

In the canonical Wnt signaling, Wnt stimulation leads to GSK-3ß inhibition, $\beta$-catenin stabilization, nuclear translocation and transcriptional activation of TCF-target genes (Ciani and Salinas 2005). Treatment with the selective GSK-3ß inhibitor Bio (Sato et al. 2004) increased the proportion of BIII-tubulin-positive neurons (data not shown). To further investigate the implication of the canonical pathway, we studied the involvement 


\section{Wnt-3a and Wnt-3 increase neurite outgrowth of SCNP-derived neurons}

When analyzing $\beta$ III-tubulin immunostained SCNP-derived neurons, we noticed an effect of Wnts in neurite development (Fig. 2D). To investigate a role of Wnt-3a and Wnt-3 signaling on neurite outgrowth, we measured the length of all BIII-tubulinpositive neurites. Wnt-3a increased total neurite length by $23 \%$ and $32 \%$ at $2 \mathrm{DIV}$ and 4DIV compared to the respective controls (Fig. 3A, 3C). Similarly, Wnt-3 also increased neurite length by about $25 \%$ and $59 \%$ at 2DIV and 4DIV, respectively, compared to the controls (Fig. 3B, 3D). These results demonstrate that Wnt-3a and Wnt-3 signaling stimulate neurite outgrowth in SCNP-derived neurons.

Next we inhibited Wnt signaling using the Wnt inhibitor Frizzled-8 cysteine-richdomain/Fc chimera $(\mathrm{Fz}-8 / \mathrm{Fc})$ that prevents $\mathrm{Wnt}$ binding to the Frizzled-LRP5/6 receptor complex (Dann et al. 2001; Hsieh et al. 1999), and Dikkopf-1 (Dkk-1) that binds to canonical Wnt co-receptors LRP5/6 (Kikuchi et al. 2009). Treatment with Wnt3a and Fz-8/Fc with or without Dkk-1 did not modify neurogenesis above control levels in SCNP cultures (Fig. 4A). However, the proportion of $\beta$ III-tubulin-positive neurons following treatment with Wnt-3 and Fz-8/Fc or Wnt-3, Fz-8/Fc and Dkk-1 decreased compared to that of Wnt-3-stimulated cultures (Fig. 4A). Furthermore, total neurite length measurements following Wnt-3a and Wnt-3 treatments together with Fz-8/Fc or 
Fz-8/Fc plus Dkk-1, respectively, showed in both cases a blockade in the Wnt-induced neurite extension of SCNP-derived neurons (Fig. 4B). These results demonstrate the specificity of the effects promoted by Wnt-3a and Wnt-3 CM.

\section{GSK-3ß inhibition from plating or on established cultures differently affects neurite outgrowth}

To dissect the signaling pathway through which Wnt-3a and Wnt-3 promote neurite outgrowth in SCNP cultures, we first investigated the consequences of inhibiting GSK33. SCNP-derived neurons treated with the selective GSK-3ß inhibitor Bio (Sato et al. 2004) or Kenpaullone that inhibits GSK-3ß, Cdks and other kinases (Bain et al. 2003) from 2DIV to 3DIV showed an increased total neurite length of $23 \%$ and $26 \%$, respectively, compared to control (Fig. 5; DIV2-3). These results are similar to the stimulation of neurite extension promoted by Wnt-3a and Wnt-3 at 3DIV (data not shown), suggesting that Wnt-3a and Wnt-3 regulate neurite outgrowth by inhibiting GSK-3ß. Interestingly, inhibiting GSK-3ß from plating up to 3DIV with Bio or Kenpaullone resulted in an average inhibition of neurite outgrowth of $34 \%$ and $28 \%$, respectively, compared to the control (Fig. 5; DIV0-3). The opposed results obtained upon GSK-3ß inhibition at different stages of neurite outgrowth in SCNP-derived neurons are in agreement with reported dual effects of GSK-3ß inhibition in axon formation vs axon elongation/branching (Garrido et al. 2007).

\section{B-catenin and TCF4 are required for the Wnt-3a- and Wnt-3-induced neurite outgrowth}

A branch of the canonical Wnt pathway diverges at the level of GSK-3ß and regulates the microtubule cytoskeleton and the axon behavior independent of $\beta$-catenin and of 
transcriptional activation (Purro et al. 2008). To study the requirement of $\beta$-catenin in the Wnt-induced neurite outgrowth, SCNP cultures were transduced with lentivirus for the expression of $\beta$-catenin shRNAs. We obtained a reduction of $\beta$-catenin total levels of $\sim 20-30 \%$ with shRNA1-2 after 5DIV (Fig. 6A). Wnt-3a and Wnt-3 induced neurite outgrowth in SCNP expressing scrambled shRNA. However, the Wnt-induced neurite outgrowth was prevented in neurons expressing B-catenin shRNAs (Fig. 6B-5C), indicating that $\beta$-catenin is required for the neurite extension induced by Wnt-3a and Wnt-3 in SCNP-derived neurons.

To study the involvement of gene transcription in the neurite outgrowth promoted by Wnt-3a and Wnt-3 we treated SCNP cultures with ActD. We used a concentration of ActD that did not affect neurite outgrowth in control neurons (Fig. 7A). However, the neurite outgrowth induced by Wnt-3a and Wnt-3 was blocked in ActD-treated cultures (Fig. 7A). We previously showed that $\triangle \mathrm{N}$-TCF4, which promoter can not bind B-catenin (Roose et al. 1999), blocks the axon outgrowth induced by Wnt-3a in hippocampal neurons (David et al. 2008). We tested whether expression of dominant negative $\Delta \mathrm{N}$ TCF4 could block the neurite outgrowth induced by Wnt-3a and Wnt-3. SCNP expressing EGFP treated with Wnt-3a or Wnt-3 for $48 \mathrm{~h}$ displayed neurites $~ 30 \%$ longer than untreated controls (Fig. 7B). However, expression of $\triangle$ N-TCF4 blocked the increase in neurite length induced by Wnt-3a and Wnt-3 (Fig. 7B). These results demonstrate that transcription by TCF4 is downstream of $\beta$-catenin in the stimulation of neurite outgrowth induced by Wnt-3a and Wnt-3 in spinal neurons. 


\section{DISCUSSION}

Here we studied the function of Wnt-3a and Wnt-3 in SCNP development. Despite high sequence homology, different Wnt-3a and Wnt-3 expression patterns (Krylova et al. 2002; Megason and McMahon 2002; Roelink and Nusse 1991) suggest distinct functions. Wnt-3a stimulated SCNP proliferation in a continued manner up to 4DIV and decreased the expression of Cdk inhibitors. In contrast, Wnt-3 raised the expression of cell cycle inhibitors and increased neurogenesis through $\beta$-catenin. Furthermore, both Wnt-3a and Wnt-3 promoted neurite outgrowth in SCNP-derived neurons through activation of the Wnt/ß-catenin canonical pathway. These effects coincide in time with the proliferation/neurogenesis effects in SCNP cultures, suggesting that Wnts stimulate proliferation/neurogenesis of SCNP and at the same time promote neurite outgrowth on differentiating neurons. Our results highlight a different control of cell cycle entry/exit by Wnt-3a and Wnt-3 signaling and demonstrate the role of canonical Wnt signaling supporting neurite outgrowth in spinal neurons.

Wnt signaling regulates embryonic and adult neurogenesis and neuronal connectivity (Ahmad-Annuar et al. 2006; Andersson et al. 2008; Castelo-Branco et al. 2003; Ciani and Salinas 2005; Chojnacki et al. 2009; Hirabayashi et al. 2004; Hirsch et al. 2007; Krylova et al. 2002; Kuwabara et al. 2009; Lee et al. 2004; Lie et al. 2005; Lu et al. 2004; Michaelidis and Lie 2008; Muroyama et al. 2002; Muroyama et al. 2004; Sousa et al. 2009). Wnt-3 secreted by astrocytes regulates adult hippocampal neurogenesis through the Wnt/ß-catenin pathway (Lie et al. 2005). Contrary to Wnt-5a and Wnt-1 that increase neurogenesis, Wnt-3a enhances proliferation from embryonic midbrain NPs (Castelo-Branco et al. 2003). In the developing spinal cord, Wnt-3a collaborates with Wnt-1 in the specification of dorsal interneurons (Lee et al. 2004; Muroyama et al. 
2002). Dorsal Wnt-1/Wnt-3a signaling also suppress the ventral program instructed by Sonic Hedgehog (Shh) by controlling the expression of Gli3 repressor (Ulloa and Marti 2009; Yu et al. 2008). Here we report that Wnt-3a and Wnt-3 increase BrdU incorporation in 2DIV SCNP. In agreement with a Wnt-3a mitogenic activity (CasteloBranco et al. 2003; Megason and McMahon 2002) Wnt-3a continued increasing SCNP proliferation at 4DIV, suggesting that Wnt-3a maintains SCNP cycling. In contrast, Wnt-3 did not affect SCNP proliferation and increased neurogenesis at 4DIV in a $\beta$ catenin-dependent manner. What determines cell cycle entry/exit and differentiation by different Wnts remains to be fully elucidated. In vivo manipulation of B-catenin levels showed that $\beta$-catenin-mediated transcriptional activation controls cell cycle progression by regulating cyclin D1-D2 expression (Chenn and Walsh 2002; Megason and McMahon 2002; Woodhead et al. 2006; Zechner et al. 2003). However, a role for Bcatenin in neuronal specification and regulating neurogenin expression, has been also demonstrated (Hirabayashi et al. 2004; Woodhead et al. 2006; Yu et al. 2008). Recently, the proneural transcription factor NeuroD1 was identified as a novel Wnt target gene in adult neurogenesis (Kuwabara et al. 2009). Our results indicate that Wnt-3a and Wnt-3 differently regulate $\mathrm{Cdk}$ inhibitor expression at 4DIV to control proliferation/differentiation. One possibility is that Wnt-3a and Wnt-3 signaling use different transcriptional co-activators resulting in the activation of proliferation or differention programs (Miyabayashi et al. 2007).

The effects promoted by Wnt-3a and Wnt-3 CM were specific as they were inhibited by the Wnt antagonists Fz-8Fc and Dkk-1. However, the blockade of the Wnt-3-induced neurogenesis observed upon Fz-8Fc and Dkk-1 co-treatments was partial. Ryk cleavage and its intracellular C-terminal domain (ICD) translocation to the nucleus is required for 
the Wnt-3-induced neurogenesis in the cortex (Lyu et al. 2008). Ryk expression in the spinal cord (Kamitori et al. 2002) would support a similar role in the SCNP-derived neurogenesis promoted by Wnt-3. However, Ryk ICD was suggested to signal independent of B-catenin (Lyu et al. 2008) and we show that Wnt-3-induced neurogenesis from SCNP is B-catenin-dependent. The possible contribution of Ryk to the Wnt-3-induced neurogenesis at the spinal cord remains to be studied.

Which are the types of neurons generated by Wnt-3 signaling? SCNP differentiate into different neuron types according to the synthesis of different neurotransmitters (Kalyani et al. 1998). Recent studies demonstrate that Wnt signaling acts in coordination with Shh in the specification of ventral cell types at the neural tube Ulloa and Marti 2009; Yu et al. 2008). Wnt signaling generates dorsal and V2 cell fates at the expense of motoneurons (Yu et al. 2008). However, floor plate expression of Wnt-4/5 specifically promotes median motor column motoneuron identity (Agalliu et al. 2009).

Dissection of the Wnt pathway activated by Wnt-3a/Wnt-3 in SCNP neurogenesis and neurite outgrowth implicates the Wnt/ß-catenin canonical pathway. GSK-3ß inhibitors mimicked Wnt-3 signaling as they stimulated neurite outgrowth on established cultures. Nevertheless, inhibition of GSK-3ß upon cell plating decreased the average neurite length. These findings suggest divergent roles for GSK3ß at early vs late stages of neurite specifation and outgrowth, in agreement with GSK3ß function in neuronal polarity and axon formation (Garrido et al. 2007; Kim et al. 2006). Furthermore, ßcatenin was required for the Wnt-3 induced neurogenesis and the neurite outgrowth induced by Wnt-3a and Wnt-3. Although total B-catenin levels decreased $~ 30 \%$ upon expression of $\beta$-catenin shRNAs, the Wnt-induced effects were completely prevented. 
These results suggest that the $\beta$-catenin nuclear signaling pool was mainly affected in SCNP-derived neurons and that the remaining $\beta$-catenin is contributed by the cadherinbound B-catenin and/or non-neuronal B-catenin pools. Finally, ActD experiments and expression of $\triangle \mathrm{N}-\mathrm{TCF} 4$ demonstrated that transcription by TCF4 is needed for the Wnt3a/Wnt-3-promoted neurite outgrowth in spinal neurons. Together these results implicate a ß-catenin-dependent transcriptional regulation of TCF4 target genes to promote neurogenesis and neurite extension in spinal progenitors and neurons.

Wnts regulate neurite development during the establishment of neuronal connections (Ciani and Salinas 2005). Wnt-3a increased neurite outgrowth in hippocampal, dorsal root ganglia and spinal neurons through TCF-driven gene transcription of target genes (present results) (David et al. 2008; Lu et al. 2004). Wnt-3 induces growth cone enlargement, axon branching and stops axon extension during the terminal differentiation of NT-3-dependent sensory axons (Krylova et al. 2002). Wnt-3a and Wnt-3 signal independent of $\beta$-catenin and transcription during sensory axon remodeling (Purro et al. 2008). These findings contrast with the requirement of TCF4driven transcription for the Wnt3a- and Wnt-3-dependent neurite outgrowth in spinal neurons. It is possible that, by activating different signaling pathways, Wnts induce different neurite behaviors (outgrowth or growth cone pausing/remodeling).

Wnt-3a mutant mice revealed that Wnt-3a is required for hippocampus formation (Lee et al. 2000) and for the expansion of CNS progenitors (Ikeya et al. 1997). However, the early embryonic lethality of Wnt-3 mutant mice (Liu et al. 1999) has hampered the in vivo analysis of the role(s) of Wnt-3 in spinal cord development. Importantly, genetic approaches demonstrated the in vivo role of Wnt signaling in the normal patterning of 
the neural tube (Ulloa and Marti 2009; Yu et al. 2008). Ectopic expression of Wnt-3a in the chick spinal cord revealed that a gradient of dorsal midline Wnt-3a controls the size of the neural tube by positive regulation of cell cycle progression (Megason and McMahon 2002). In contrast, Wnt-3 that displays a dorsal broad domain of expression increased neuronal differentiation (Megason and McMahon 2002). This data supports our findings on the Wnt-3- and Wnt-3a-induced neurogenesis and proliferation, respectively, in cultured mouse SCNP. Moreover, we uncover a transient proliferation effect of Wnt-3 and demonstrate the stimulation of neurite outgrowth by Wnt-3a and Wnt-3 in SCNP-derived neurons. Thus, our results show that activation of the Wnt/Bcatenin canonical pathway regulates cell cycle entry/exit and neurogenesis in neural precursors and leads to neuritogenesis in newborn neurons. This work illustrates the complexity of Wnt signaling (and of the canonical pathway), comprising several family members that perform partially redundant roles through the canonical pathway and induce different cell responses in a context and time-dependent manner (Yu et al. 2008). In addition, our findings suggest that components of the Wnt/ß-catenin pathway could be considered as therapeutic targets for the treatment of neurodegenerative diseases and nerve injury. Interestingly Wnt-3 is expressed in ependymal cells lining the central canal (Krylova et al. 2002), a cell population that could be considered the adult spinal neural stem cell (Chojnacki et al. 2009) and that responds to spinal cord injury (Meletis et al. 2008).

Acknowledgments. We are grateful to A. Yeramian for the B-catenin shRNAs, to A. Münsterberg for Rat1B cell lines, H. Clevers for DN-TCF4, D. Trono for lentiviral vectors and to J.X. Comella, T. Iglesias, M. Aldea and C. Gallego for helpful discussion. M.D. was a fellow of Instituto de Salud Carlos III and University of Lleida. 


\section{REFERENCES}

Agalliu D, Takada S, Agalliu I, McMahon AP, Jessell TM. 2009. Motor neurons with axial muscle projections specified by Wnt4/5 signaling. Neuron 61(5):708-720.

Ahmad-Annuar A, Ciani L, Simeonidis I, Herreros J, Fredj NB, Rosso SB, Hall A, Brickley S, Salinas PC. 2006. Signaling across the synapse: a role for Wnt and Dishevelled in presynaptic assembly and neurotransmitter release. J Cell Biol 174(1):127-139.

Andersson ER, Prakash N, Cajanek L, Minina E, Bryja V, Bryjova L, Yamaguchi TP, Hall AC, Wurst W, Arenas E. 2008. Wnt5a regulates ventral midbrain morphogenesis and the development of A9-A10 dopaminergic cells in vivo. PLoS ONE 3(10):e3517.

Bain J, McLauchlan H, Elliott M, Cohen P. 2003. The specificities of protein kinase inhibitors: an update. Biochem J 371(Pt 1):199-204.

Castelo-Branco G, Rawal N, Arenas E. 2004. GSK-3beta inhibition/beta-catenin stabilization in ventral midbrain precursors increases differentiation into dopamine neurons. J Cell Sci 117(Pt 24):5731-5737.

Castelo-Branco G, Wagner J, Rodriguez FJ, Kele J, Sousa K, Rawal N, Pasolli HA, Fuchs E, Kitajewski J, Arenas E. 2003. Differential regulation of midbrain dopaminergic neuron development by Wnt-1, Wnt-3a, and Wnt-5a. Proc Natl Acad Sci U S A 100(22):12747-12752.

Ciani L, Salinas PC. 2005. WNTs in the vertebrate nervous system: from patterning to neuronal connectivity. Nat Rev Neurosci 6(5):351-362.

Chenn A, Walsh CA. 2002. Regulation of cerebral cortical size by control of cell cycle exit in neural precursors. Science 297(5580):365-369.

Chojnacki AK, Mak GK, Weiss S. 2009. Identity crisis for adult periventricular neural stem cells: subventricular zone astrocytes, ependymal cells or both? Nat Rev Neurosci 10(2):153-163.

Dann CE, Hsieh JC, Rattner A, Sharma D, Nathans J, Leahy DJ. 2001. Insights into Wnt binding and signalling from the structures of two Frizzled cysteine-rich domains. Nature 412(6842):86-90.

David MD, Yeramian A, Dunach M, Llovera M, Canti C, de Herreros AG, Comella JX, Herreros J. 2008. Signalling by neurotrophins and hepatocyte growth factor regulates axon morphogenesis by differential \{beta\}-catenin phosphorylation. J Cell Sci 121(Pt 16):2718-2730.

Garrido JJ, Simon D, Varea O, Wandosell F. 2007. GSK3 alpha and GSK3 beta are necessary for axon formation. FEBS Lett 581(8):1579-1586.

Gulacsi AA, Anderson SA. 2008. Beta-catenin-mediated Wnt signaling regulates neurogenesis in the ventral telencephalon. Nat Neurosci 11(12):1383-1391.

Hirabayashi Y, Itoh Y, Tabata H, Nakajima K, Akiyama T, Masuyama N, Gotoh Y. 2004. The Wnt/beta-catenin pathway directs neuronal differentiation of cortical neural precursor cells. Development 131(12):2791-2801.

Hirsch C, Campano LM, Wohrle S, Hecht A. 2007. Canonical Wnt signaling transiently stimulates proliferation and enhances neurogenesis in neonatal neural progenitor cultures. Exp Cell Res 313(3):572-587.

Hsieh JC, Rattner A, Smallwood PM, Nathans J. 1999. Biochemical characterization of Wnt-frizzled interactions using a soluble, biologically active vertebrate Wnt protein. Proc Natl Acad Sci U S A 96(7):3546-3551.

Ikeya M, Lee SM, Johnson JE, McMahon AP, Takada S. 1997. Wnt signalling required for expansion of neural crest and CNS progenitors. Nature 389(6654):966-970. 
Kalyani AJ, Piper D, Mujtaba T, Lucero MT, Rao MS. 1998. Spinal cord neuronal precursors generate multiple neuronal phenotypes in culture. J Neurosci 18(19):7856-7868.

Kamitori K, Machide M, Tomita K, Nakafuku M, Kohsaka S. 2002. Cell-type-specific expression of protein tyrosine kinase-related receptor RYK in the central nervous system of the rat. Brain Res Mol Brain Res 104(2):255-266.

Kikuchi A, Yamamoto H, Sato A. 2009. Selective activation mechanisms of Wnt signaling pathways. Trends Cell Biol 19(3):119-129.

Kim WY, Zhou FQ, Zhou J, Yokota Y, Wang YM, Yoshimura T, Kaibuchi K, Woodgett JR, Anton ES, Snider WD. 2006. Essential roles for GSK-3s and GSK-3-primed substrates in neurotrophin-induced and hippocampal axon growth. Neuron 52(6):981-996.

Krylova O, Herreros J, Cleverley KE, Ehler E, Henriquez JP, Hughes SM, Salinas PC. 2002. WNT-3, expressed by motoneurons, regulates terminal arborization of neurotrophin-3-responsive spinal sensory neurons. Neuron 35(6):1043-1056.

Kuwabara T, Hsieh J, Muotri A, Yeo G, Warashina M, Lie DC, Moore L, Nakashima K, Asashima M, Gage FH. 2009. Wnt-mediated activation of NeuroD1 and retro-elements during adult neurogenesis. Nat Neurosci 12(9):1097-1105.

Lee HY, Kleber M, Hari L, Brault V, Suter U, Taketo MM, Kemler R, Sommer L. 2004. Instructive role of Wnt/beta-catenin in sensory fate specification in neural crest stem cells. Science 303(5660):1020-1023.

Lee SM, Tole S, Grove E, McMahon AP. 2000. A local Wnt-3a signal is required for development of the mammalian hippocampus. Development 127(3):457-467.

Lie DC, Colamarino SA, Song HJ, Desire L, Mira H, Consiglio A, Lein ES, Jessberger S, Lansford H, Dearie AR, Gage FH. 2005. Wnt signalling regulates adult hippocampal neurogenesis. Nature 437(7063):1370-1375.

Liu P, Wakamiya M, Shea MJ, Albrecht U, Behringer RR, Bradley A. 1999. Requirement for Wnt3 in vertebrate axis formation. Nat Genet 22(4):361-365.

Logan CY, Nusse R. 2004. The Wnt signaling pathway in development and disease. Annu Rev Cell Dev Biol 20:781-810.

Lu W, Yamamoto V, Ortega B, Baltimore D. 2004. Mammalian Ryk is a Wnt coreceptor required for stimulation of neurite outgrowth. Cell 119(1):97-108.

Lyu J, Yamamoto V, Lu W. 2008. Cleavage of the Wnt receptor Ryk regulates neuronal differentiation during cortical neurogenesis. Dev Cell 15(5):773-780.

Megason SG, McMahon AP. 2002. A mitogen gradient of dorsal midline Wnts organizes growth in the CNS. Development 129(9):2087-2098.

Meletis K, Barnabe-Heider F, Carlen M, Evergren E, Tomilin N, Shupliakov O, Frisen J. 2008. Spinal cord injury reveals multilineage differentiation of ependymal cells. PLoS Biol 6(7):e182.

Michaelidis TM, Lie DC. 2008. Wnt signaling and neural stem cells: caught in the Wnt web. Cell Tissue Res 331(1):193-210.

Miyabayashi T, Teo JL, Yamamoto M, McMillan M, Nguyen C, Kahn M. 2007. Wnt/beta-catenin/CBP signaling maintains long-term murine embryonic stem cell pluripotency. Proc Natl Acad Sci U S A 104(13):5668-5673.

Murashov AK, Pak ES, Hendricks WA, Owensby JP, Sierpinski PL, Tatko LM, Fletcher PL. 2005. Directed differentiation of embryonic stem cells into dorsal interneurons. Faseb J 19(2):252-254.

Muroyama Y, Fujihara M, Ikeya M, Kondoh H, Takada S. 2002. Wnt signaling plays an essential role in neuronal specification of the dorsal spinal cord. Genes Dev 16(5):548-553. 
Muroyama Y, Kondoh H, Takada S. 2004. Wnt proteins promote neuronal differentiation in neural stem cell culture. Biochem Biophys Res Commun 313(4):915-921.

Otero JJ, Fu W, Kan L, Cuadra AE, Kessler JA. 2004. Beta-catenin signaling is required for neural differentiation of embryonic stem cells. Development 131(15):35453557.

Parr BA, Shea MJ, Vassileva G, McMahon AP. 1993. Mouse Wnt genes exhibit discrete domains of expression in the early embryonic CNS and limb buds. Development 119(1):247-261.

Purro SA, Ciani L, Hoyos-Flight M, Stamatakou E, Siomou E, Salinas PC. 2008. Wnt regulates axon behavior through changes in microtubule growth directionality: a new role for adenomatous polyposis coli. J Neurosci 28(34):8644-8654.

Qu Q, Sun G, Li W, Yang S, Ye P, Zhao C, Yu RT, Gage FH, Evans RM, Shi Y. Orphan nuclear receptor TLX activates Wnt/beta-catenin signalling to stimulate neural stem cell proliferation and self-renewal. Nat Cell Biol 12(1):31-40; sup pp 31-39.

Roelink H, Nusse R. 1991. Expression of two members of the Wnt family during mouse development--restricted temporal and spatial patterns in the developing neural tube. Genes Dev 5(3):381-388.

Roose J, Huls G, van Beest M, Moerer P, van der Horn K, Goldschmeding R, Logtenberg T, Clevers H. 1999. Synergy between tumor suppressor APC and the beta-catenin-Tcf4 target Tcf1. Science 285(5435):1923-1926.

Sanchez-Camacho C, Bovolenta P. 2009. Emerging mechanisms in morphogenmediated axon guidance. Bioessays 31(10):1013-1025.

Sato N, Meijer L, Skaltsounis L, Greengard P, Brivanlou AH. 2004. Maintenance of pluripotency in human and mouse embryonic stem cells through activation of Wnt signaling by a pharmacological GSK-3-specific inhibitor. Nat Med 10(1):55-63.

Sousa KM, Villaescusa JC, Cajanek L, Ondr JK, Castelo-Branco G, Hofstra W, Bryja V, Palmberg C, Bergman T, Wainwright B, Lang RA, Arenas E. 2009. WNT2 regulates progenitor proliferation in the developing ventral midbrain. $\mathrm{J}$ Biol Chem.

Ulloa F, Marti E. 2009. Wnt won the war: Antagonistic role of Wnt over Shh controls dorso-ventral patterning of the vertebrate neural tube. Dev Dyn 239(1):69-76.

Woodhead GJ, Mutch CA, Olson EC, Chenn A. 2006. Cell-autonomous beta-catenin signaling regulates cortical precursor proliferation. J Neurosci 26(48):1262012630.

Wu S, Suzuki Y, Ejiri Y, Noda T, Bai H, Kitada M, Kataoka K, Ohta M, Chou H, Ide C. 2003. Bone marrow stromal cells enhance differentiation of cocultured neurosphere cells and promote regeneration of injured spinal cord. J Neurosci Res 72(3):343-351.

Yu W, McDonnell K, Taketo MM, Bai CB. 2008. Wnt signaling determines ventral spinal cord cell fates in a time-dependent manner. Development 135(22):36873696.

Zechner D, Fujita Y, Hulsken J, Muller T, Walther I, Taketo MM, Crenshaw EB, 3rd, Birchmeier W, Birchmeier C. 2003. beta-Catenin signals regulate cell growth and the balance between progenitor cell expansion and differentiation in the nervous system. Dev Biol 258(2):406-418. 


\section{Figure legends}

\section{Figure 1. Wnt-3a and Wnt-3 produce a sustained or transient increase of SCNP} proliferation. A) Increase in the percentage of SCNP in S phase in Wnt-treated cells normalized to controls at 2DIV. B) SCNP cultures treated with Wnt-3 and immunostained for nestin show increased numbers of neural precursors that incorporate BrdU at 2DIV (asterisks). Arrows point to small neuroblasts. (Bar= $65 \mu \mathrm{m}$ ). C) BrdU incorporation in small neuroblasts (left panels) and in total SCNP (right panels) show that Wnt-3a and Wnt-3 increase proliferation at 2DIV. However at 4DIV only Wnt-3a maintains SCNP proliferation. D) Expression levels of p57 and p27 Cdk inhibitors in SCNP treated with Wnt-3a or Wnt-3 normalized to the respective controls show decreased levels of p57 and p27 following Wnt-3a treatment and increased levels of p57 upon Wnt-3 treatment at 4DIV. The ratio Wnt-3/Wnt-3a illustrates the increase of Cdk inhibitors expression by Wnt-3 compared to the effect of Wnt-3a. $(* p \leq 0.05, * * p \leq 0.01$ and $* * * \mathrm{p} \leq 0.001 ; \mathrm{n}=3-5)$.

Figure 2. Wnt-3 increases neurogenesis by canonical Wnt/B-catenin signaling. A) Wnt-3, but not Wnt-3a, increases the percentage of BIII-tubulin-positive SCNP-derived neurons at 4DIV. Wnt-3-treated SCNP cultures show increased number of BIII-tubulinimmunoreactive neurons referred to the total number of cells (stained by Hoechst) compared to control $(\mathrm{Bar}=65 \mu \mathrm{m})$. B) The neurogenesis induced by Wnt-3 treatment (3-5DIV) in SCNP expressing scrambled shRNA is abolished by $\beta$-catenin shRNA. C) Wnt-3 increases neurite extension in SCNP-derived post-mitotic neurons, coimmunostained for BIII-tubulin and the transcription factor NeuN at 4DIV (Bar= 40 $\mu \mathrm{m})(* \mathrm{p} \leq 0.05, * * \mathrm{p} \leq 0.01$ and $* * * \mathrm{p} \leq 0.001 ; \mathrm{n}=3-4)$. 
Figure 3. Wnt-3a and Wnt-3 induce neurite outgrowth in SCNP-derived neurons.

A, B) Wnt-3a and Wnt-3 increase neurite extension compared to controls at 2DIV and 4DIV (Bar= $40 \mu \mathrm{m}) . \mathrm{C}$, D) Total neurite length values for control and Wnt-treated SCNP-derived neurons at 2DIV and 4DIV $(* * \mathrm{p} \leq 0.01$ and $* * * \mathrm{p} \leq 0.001 ; \mathrm{n}=4-6)$.

\section{Figure 4. Effects of Dkk-1 and Fz-8/Fc on neurogenesis and neurite outgrowth at} 4DIV. A) Wnt-3 (bottom) but not Wnt-3a (top) increase neurogenesis (estimated as the $\%$ of $\beta$ III-tubulin-positive neurons) from SCNP, which is partially inhibited by high doses of Dkk-1 and Fz-8/Fc. B) Fz-8/Fc alone or together with Dkk-1 block the increase in neurite extension induced by Wnt-3a (top) and Wnt-3 (bottom), pointing at the specificity of the Wnt effects $(* \mathrm{p} \leq 0.05, * *, \mathrm{p} \leq 0.01, * * * \mathrm{p} \leq 0.001$ when comparing to the corrresponding control; $\$ \mathrm{p} \leq 0.05, \$ \$ \mathrm{p} \leq 0.01$ when comparing to Wnt-treatment without Dkk-1 and Fz-8/Fc; n=3-4). Note the decreased neurite extension obtained upon Fz-8/Fc treatment in the absence of exogenous Wnt-3a, suggesting the role of endogenous Wnts in this process.

Figure 5. GSK-3ß inhibition upon plating reduces neurite outgrowth, whereas later GSK-3ß inhibition mimics the Wnt-induced neurite extension in SCNPderived neurons. A) Schematic representation of the canonical Wnt/ $\beta$-catenin pathway. Wnt binding to the Fz-LRP5/6 receptor complex recruits Dvl and results in the inhibition of GSK3- $\beta$, disassembly of the destruction complex involving GSK3- $\beta$, $\beta$ catenin, APC, Axin and CK1 and accumulation of $\beta$-catenin in the cytosol that avoids degradation. $\beta$-catenin nuclear translocation and transcriptional regulation of TCF/LEF target genes. A branch of the pathway diverges at the level of GSK3- $\beta$ and regulates the cytoskeleton independent of $\beta$-catenin (Ciani and Salinas 2005; Sanchez-Camacho and 
Bovolenta 2009). B) SCNP were treated with Bio and Kenpaullone from plating (DIV03) or overnight on pre-established adherent cultures (DIV2-3). Note the short processes of SCNP-derived neurons immunostained for $\beta$ III-tubulin treated with Bio from plating (arrows). C) Total neurite length values indicate that GSK-3ß inhibition upon plating results in neurites shorter than in control, whereas GSK-3ß inhibition from DIV2-3 stimulates neurite extension $(\operatorname{Bar}=130 \mu \mathrm{m})(* \mathrm{p} \leq 0.05$ and $* * * \mathrm{p} \leq 0.001 ; \mathrm{n}=4)$

Figure 6. B-catenin is required for the Wnt-3a- and Wnt-3-induced neurite extension of SCNP-derived neurons. A) Western blot showing ß-catenin levels in non-infected (NI), expressing scrambled shRNA (scr) or ß-catenin shRNA (sh) \#2 and \#1 SCNP cultures at 5DIV. B-actin was used as loading control. B) BIII-tubulinimmunostained SCNP-derived neurons expressing scrambled or ß-catenin shRNA2 treated with Wnt-3a or Wnt-3 $(\mathrm{Bar}=40 \mu \mathrm{m})$. C) Total neurite length values indicate that Wnt-3a and Wnt-3 stimulate neurite outgrowth in spinal neurons expressing scrambled shRNA, but not upon expression of $\beta$-catenin $\operatorname{shRNAs}(* \mathrm{p} \leq 0.05 ; \mathrm{n}=3)$.

\section{Figure 7. TCF4-driven transcription is required for the Wnt-induced neurite} outgrowth of spinal neurons. A) Co-treatment with ActD blocks the Wnt-3a- and Wnt-3-induced increase in neurite length in SCNP-derived neurons immunostained for $\beta$ III-tubulin. B) SCNP-derived neurons expressing EGFP (control) or EGFP plus $\Delta \mathrm{N}$ TCF4 treated with Wnt-3 $($ Bar $=65 \mu \mathrm{m})$. C) Neurite length values normalized to controls show that $\triangle \mathrm{N}-\mathrm{TCF} 4$ blocks the Wnt-induced neurite extension observed in controls $(* \mathrm{p} \leq 0.05$ and $* * \mathrm{p} \leq 0.01 ; \mathrm{n}=3)$. 
Figure 1. David et al.

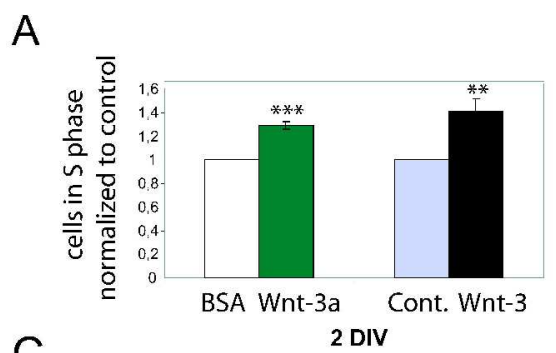

B

C
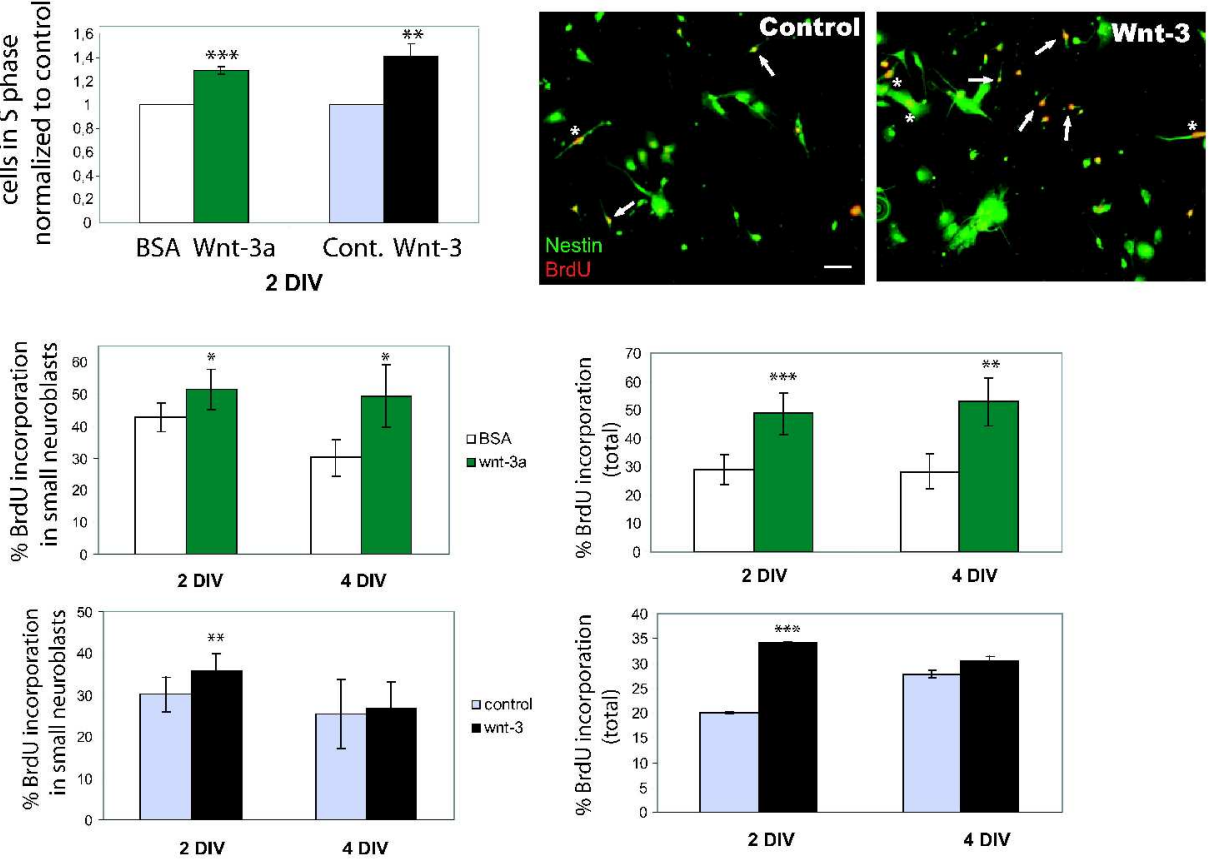

D
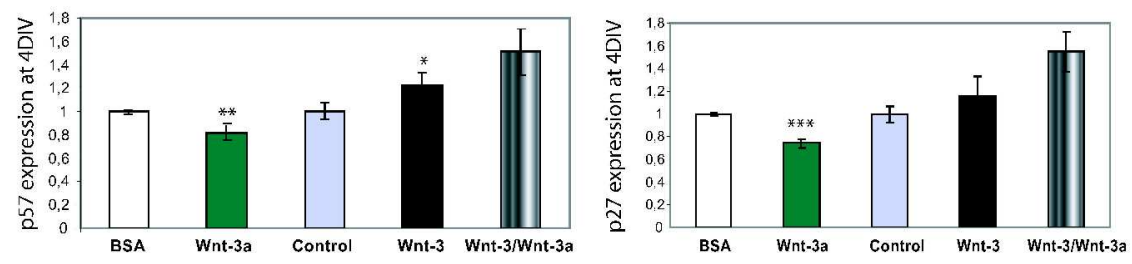

Figure 1. Wnt-3a and Wnt-3 produce a sustained or transient increase of SCNP proliferation. A) Increase in the percentage of SCNP in S phase in Wnt-treated cells normalized to controls at 2DIV.

B) SCNP cultures treated with Wnt-3 and immunostained for nestin show increased numbers of neural precursors that incorporate BrdU at 2DIV (asterisks). Arrows point to small neuroblasts.

(Bar $=65 \mu \mathrm{m}$ ). C) BrdU incorporation in small neuroblasts (left panels) and in total SCNP (right panels) show that Wnt-3a and Wnt-3 increase proliferation at 2DIV. However at 4DIV only Wnt-3a maintains SCNP proliferation. D) Expression levels of p57 and p27 Cdk inhibitors in SCNP treated with Wnt-3a or Wnt-3 normalized to the respective controls show decreased levels of p57 and p27 following Wnt-3a treatment and increased levels of p57 upon Wnt-3 treatment at 4DIV. The ratio Wnt-3/Wnt-3a illustrates the increase of Cdk inhibitors expression by Wnt-3 compared to the effect of Wnt-3a. (* $\mathrm{p} \leq 0.05, * * \mathrm{p} \leq 0.01$ and $* * * \mathrm{p} \leq 0.001 ; \mathrm{n}=3-5)$. $198 \times 202 \mathrm{~mm}(600 \times 600 \mathrm{DPI})$ 
Figure 2. David et al.

A
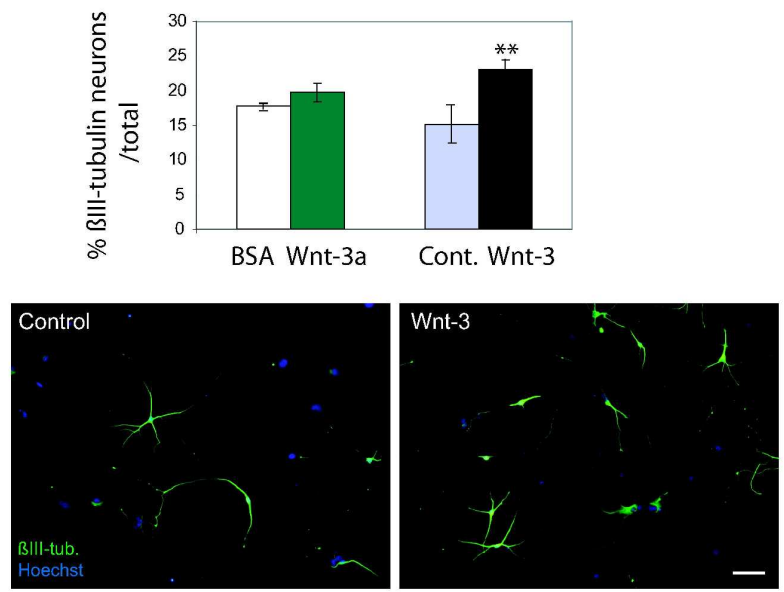

B

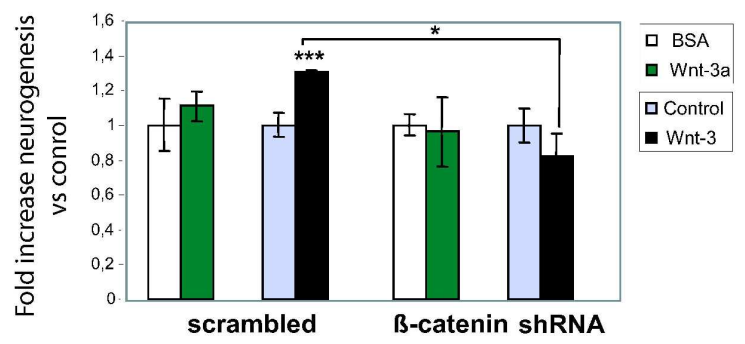

C

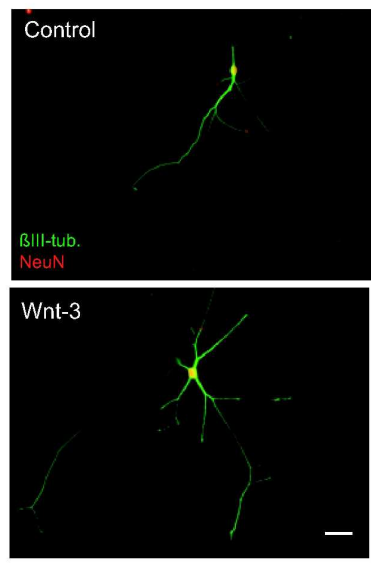

Figure 2. Wnt-3 increases neurogenesis by canonical Wnt/B-catenin signaling. A) Wnt-3, but not Wnt-3a, increases the percentage of BIII-tubulin-positive SCNP-derived neurons at 4DIV. Wnt-3treated SCNP cultures show increased number of BIII-tubulin-immunoreactive neurons referred to

the total number of cells (stained by Hoechst) compared to control (Bar $=65 \mu \mathrm{m})$. B) The

neurogenesis induced by Wnt-3 treatment (3-5DIV) in SCNP expressing scrambled shRNA is abolished by $\beta$-catenin shRNA. C) Wnt-3 increases neurite extension in SCNP-derived post-mitotic neurons, co-immunostained for BIII-tubulin and the transcription factor NeuN at 4DIV $($ Bar $=40 \mu \mathrm{m})$

$$
(* \mathrm{p} \leq 0.05, * * \mathrm{p} \leq 0.01 \text { and } * * * \mathrm{p} \leq 0.001 ; \mathrm{n}=3-4) \text {. }
$$

$184 \times 162 \mathrm{~mm}(600 \times 600 \mathrm{DPI})$ 

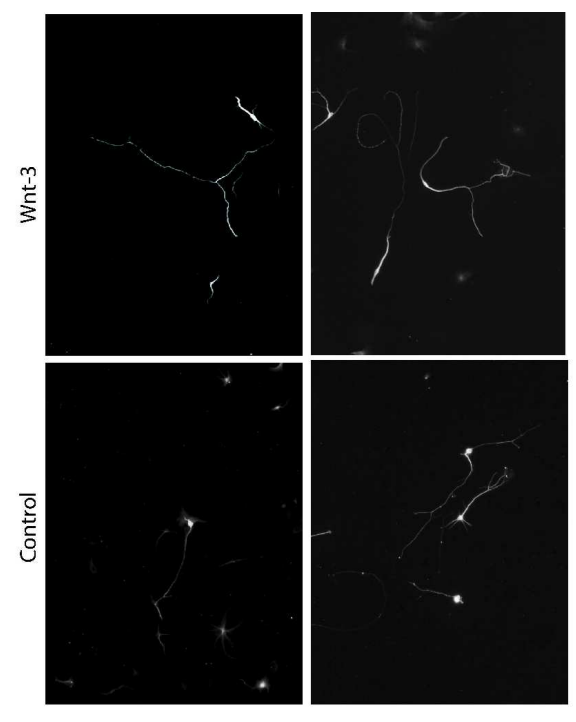

$\infty$

$\mathrm{NOZ}$ NOt
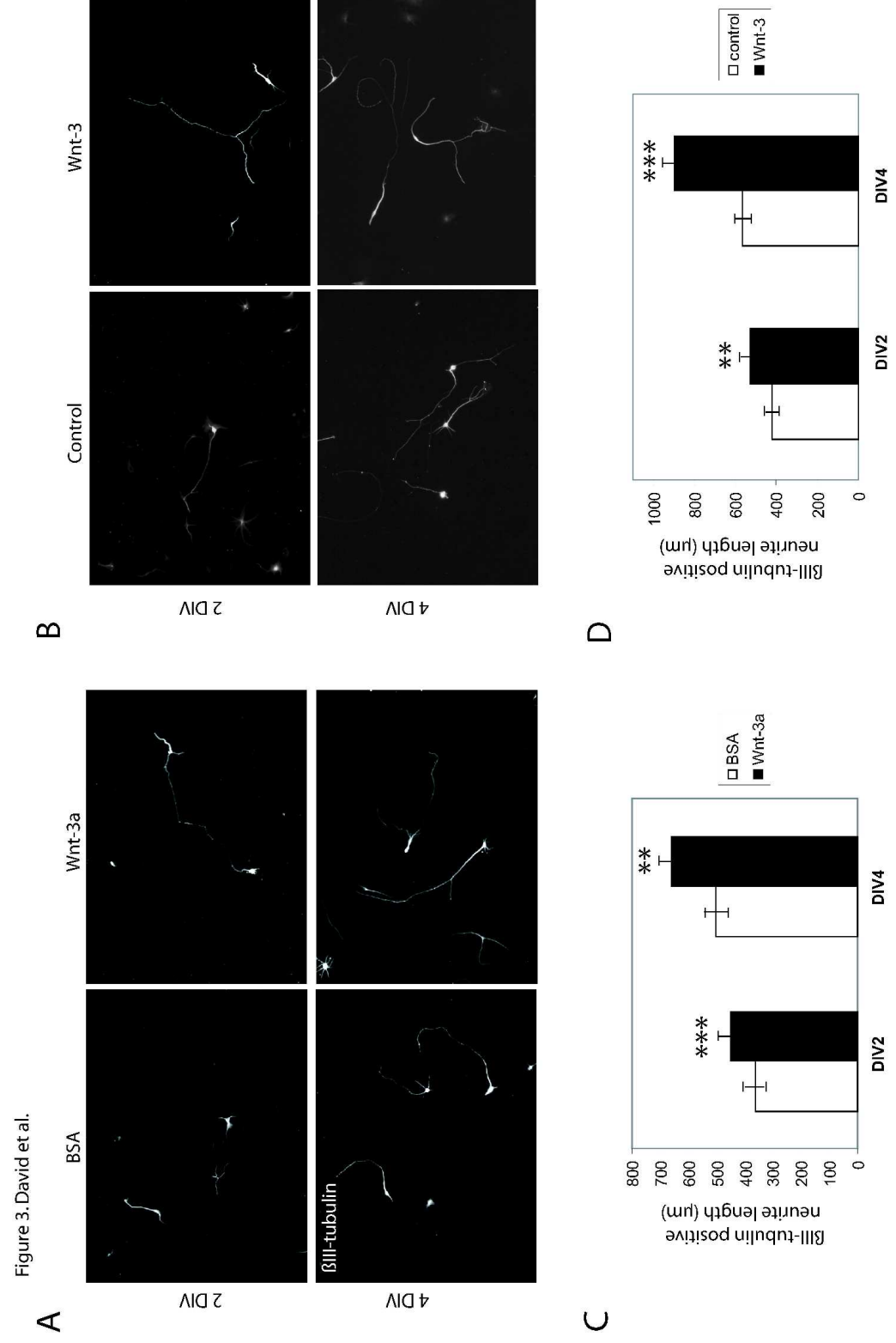

0

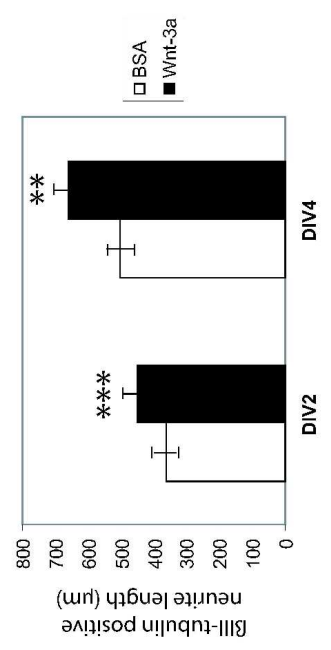

Figure 3. Wnt-3a and Wnt-3 induce neurite outgrowth in SCNP-derived neurons. A, B) Wnt-3a and Wnt-3 increase neurite extension compared to controls at 2DIV and 4DIV (Bar $=40 \mu \mathrm{m})$. C, D) Total neurite length values for control and Wnt-treated SCNP-derived neurons at 2DIV and 4DIV $(* * p \leq$ 0.01 and $* * * \mathrm{p} \leq 0.001 ; \mathrm{n}=4-6)$. $194 \times 287 \mathrm{~mm}(600 \times 600 \mathrm{DPI})$ 
Figure 4. David et al.

A

Neurogenesis
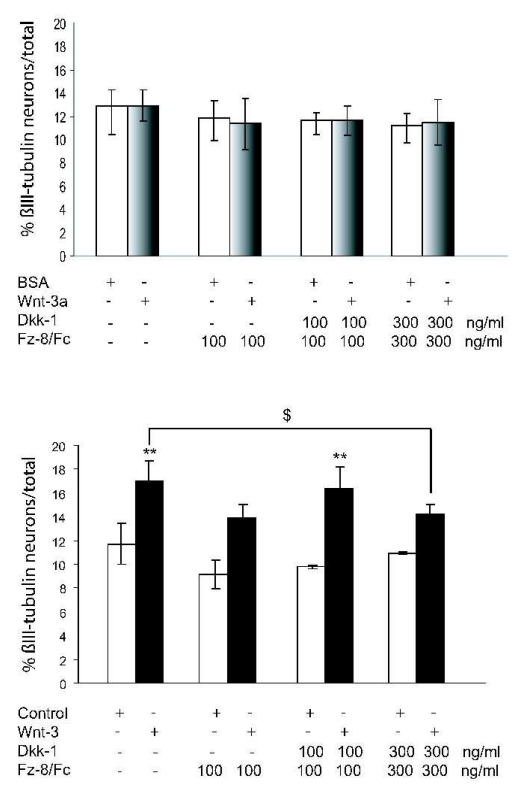
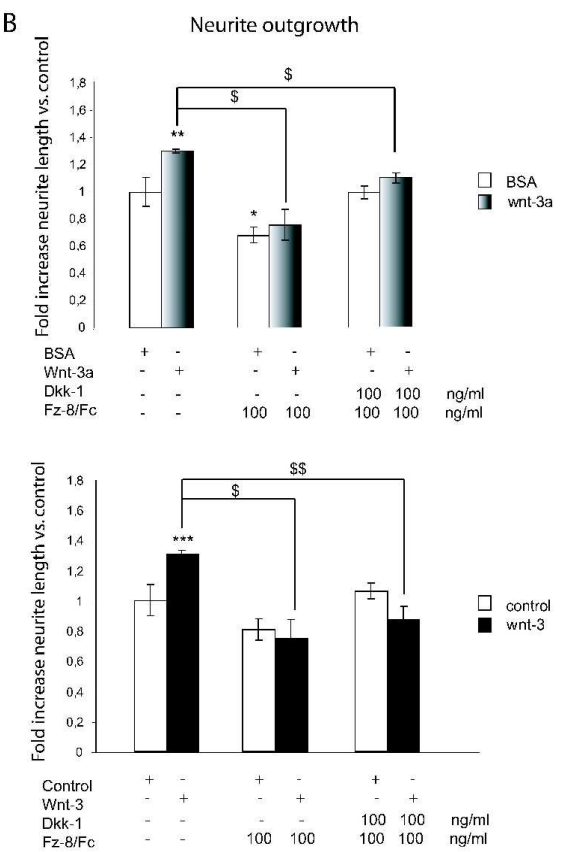

Figure 4. Effects of Dkk-1 and Fz-8/Fc on neurogenesis and neurite outgrowth at 4DIV. A) Wnt-3 (bottom) but not Wnt-3a (top) increase neurogenesis (estimated as the $\%$ of $\beta I I I-t u b u l i n-p o s i t i v e$ neurons) from SCNP, which is partially inhibited by high doses of Dkk-1 and Fz-8/Fc. B) Fz-8/Fc alone or together with Dkk-1 block the increase in neurite extension induced by Wnt-3a (top) and Wnt-3 (bottom), pointing at the specificity of the Wnt effects $(* p \leq 0.05, * *, p \leq 0.01, * * * p \leq 0.001$ when comparing to the corrresponding control; $\$ p \leq 0.05, \$ \$ p \leq 0.01$ when comparing to Wnttreatment without Dkk-1 and $\mathrm{Fz}-8 / \mathrm{Fc} ; \mathrm{n}=3-4)$. Note the decreased neurite extension obtained upon $\mathrm{Fz}-8 / \mathrm{Fc}$ treatment in the absence of exogenous Wnt-3a, suggesting the role of endogenous Wnts in this process.

$294 \times 203 \mathrm{~mm}(600 \times 600 \mathrm{DPI})$ 
A Canonical $W n t / \beta$-catenin signalling

B
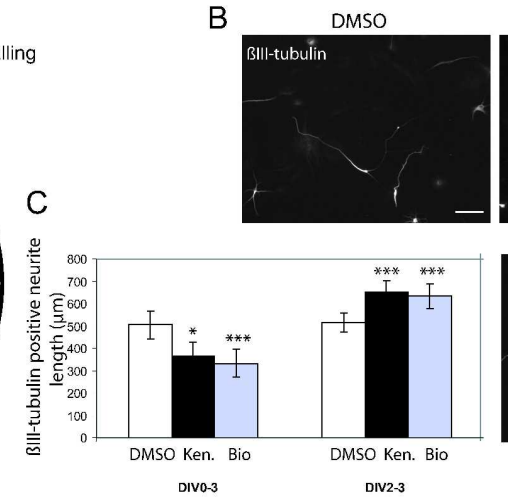

Bio (DIV0-3)

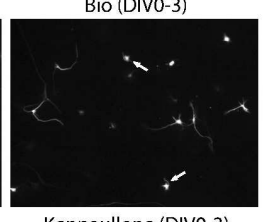

Kenpaullone (DIV0-3)

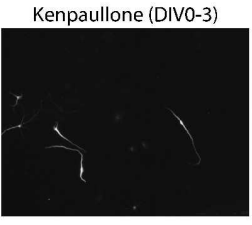

Bio (DIV2-3)

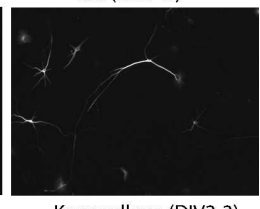

Kenpaullone (DIV2-3)

Figure 5. David et al.

Figure 5. GSK-3B inhibition upon plating reduces neurite outgrowth, whereas later GSK-3B inhibition mimics the Wnt-induced neurite extension in SCNP-derived neurons. A) Schematic representation of the canonical Wnt/ $\beta$-catenin pathway.

Wnt binding to the Fz-LRP5/6 receptor complex recruits Dvl and results in the inhibition of GSK3- $\beta$, disassembly of the destruction complex involving GSK3- $\beta, \beta$-catenin, APC, Axin and CK1 and accumulation of $\beta$-catenin in the cytosol that avoids degradation. $\beta$-catenin nuclear translocation and transcriptional regulation of TCF/LEF target genes. A branch of the pathway diverges at the level of GSK3- $\beta$ and regulates the cytoskeleton independent of $\beta$-catenin (Ciani and Salinas 2005; Sanchez-Camacho and Bovolenta 2009). B) SCNP were treated with Bio and Kenpaullone from plating (DIV0-3) or overnight on pre-established adherent cultures (DIV2-3). Note the short processes of SCNP-derived neurons immunostained for BIII-tubulin treated with Bio from plating (arrows). C) Total neurite length values indicate that GSK-3B inhibition upon plating results in neurites shorter than in control, whereas GSK-3B inhibition from DIV2-3 stimulates neurite extension $(\mathrm{Bar}=130 \mu \mathrm{m})(* \mathrm{p} \leq 0.05$ and $* * * \mathrm{p} \leq 0.001 ; \mathrm{n}=4)$ 
Figure 6. David et al.

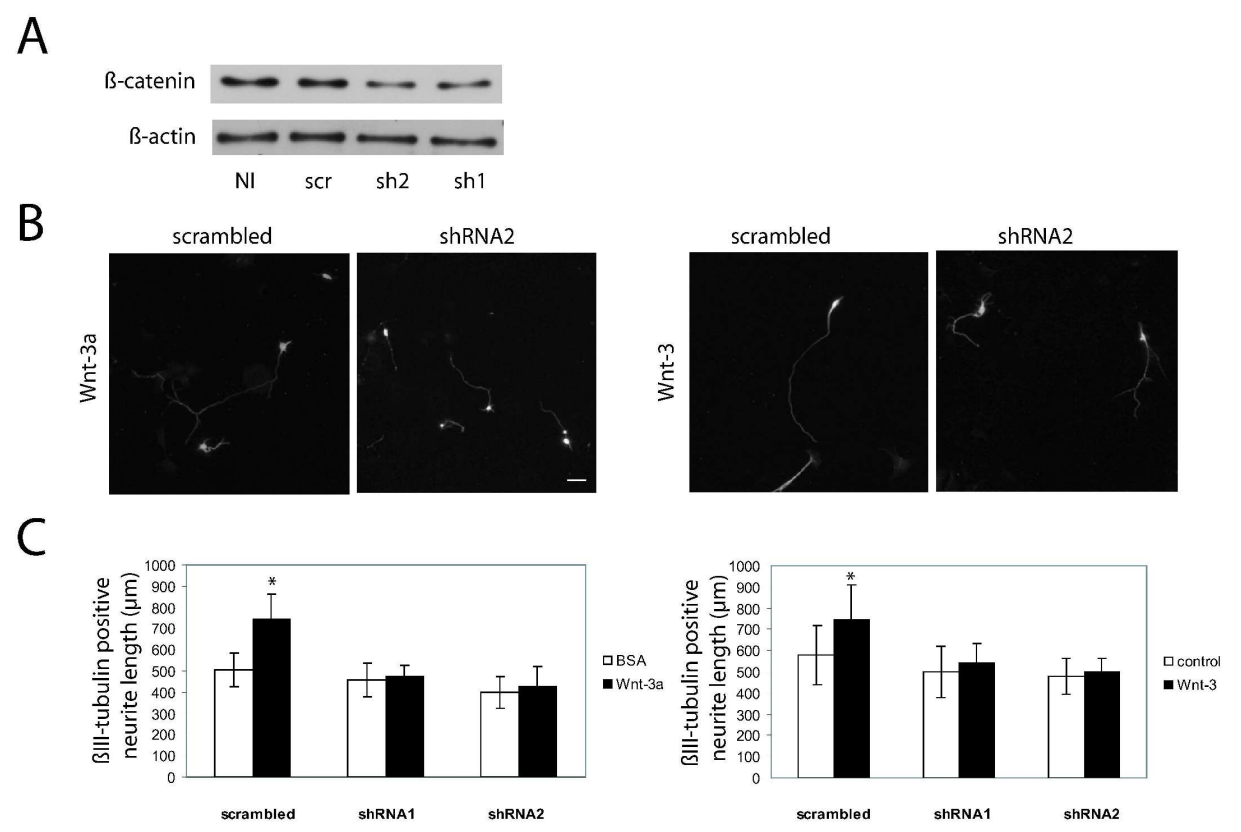

Figure 6. B-catenin is required for the Wnt-3a- and Wnt-3-induced neurite extension of SCNPderived neurons. A) Western blot showing B-catenin levels in non-infected (NI), expressing scrambled shRNA (scr) or B-catenin shRNA (sh) \#2 and \#1 SCNP cultures at 5DIV. B-actin was used as loading control. B) BIII-tubulin-immunostained SCNP-derived neurons expressing scrambled or $B$-catenin shRNA2 treated with Wnt-3a or Wnt-3 $(B a r=40 \mu \mathrm{m}) . C)$ Total neurite length values indicate that Wnt-3a and Wnt-3 stimulate neurite outgrowth in spinal neurons expressing scrambled shRNA, but not upon expression of B-catenin shRNAs (* $p \leq 0.05 ; n=3)$. $196 \times 141 \mathrm{~mm}(600 \times 600 \mathrm{DPI})$ 
Figure 7. David et al.

A

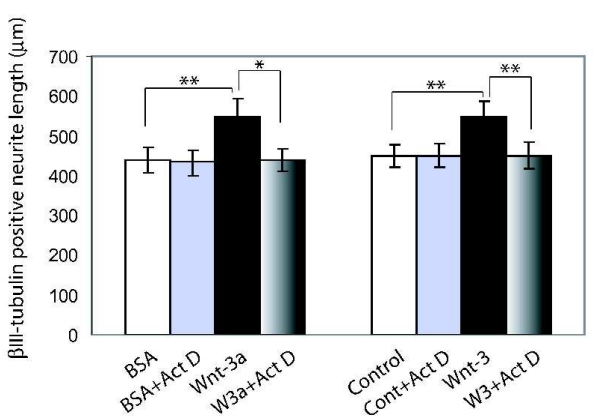

B
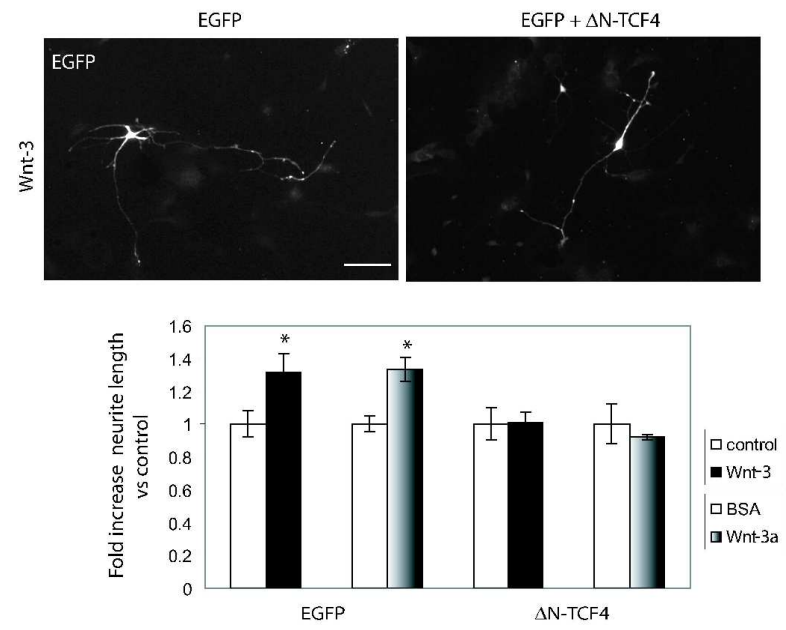

Figure 7. TCF4-driven transcription is required for the Wnt-induced neurite outgrowth of spinal neurons. A) Co-treatment with ActD blocks the Wnt-3a- and Wnt-3-induced increase in neurite length in SCNP-derived neurons immunostained for $\beta I I I$-tubulin. B) SCNP-derived neurons expressing EGFP (control) or EGFP plus $\Delta \mathrm{N}$-TCF4 treated with Wnt-3 (Bar $=65 \mu \mathrm{m})$. C) Neurite length values normalized to controls show that $\triangle \mathrm{N}$-TCF4 blocks the Wnt-induced neurite extension observed in controls (* $\mathrm{p} \leq 0.05$ and $* * \mathrm{p} \leq 0.01 ; \mathrm{n}=3)$. $221 \times 199 \mathrm{~mm}(600 \times 600 \mathrm{DPI})$ 